\title{
Genetic population structure of an anchialine shrimp, Metabetaeus lohena (Crustacea: Alpheidae), in the Hawaiian Islands
}

\author{
Atlantis Russ ${ }^{1,2, *}$, S.R. Santos $^{3}$ \& C. Muir ${ }^{1}$ \\ 1. Biology Department, University of Hawaii at Hilo, 200 West Kawili Street, Hilo, HI 96720, USA, fax: (520) 626- \\ 5097; aruss@email.arizona.edu \\ 2. Genetics Graduate Interdisciplinary Program, University of Arizona, 1548 E. Drachman St, Tucson, AZ 85719, \\ USA. \\ 3. Department of Biological Sciences and Cell \& Molecular Biosciences Peak Program, Auburn University, 101 Life \\ Sciences Building, Auburn, Alabama 36849, USA. \\ * Corresponding author.
}

Received 10-III-2009. Corrected 25-VIII-2009. Accepted 25-IX-2009.

\begin{abstract}
Anchialine habitats in the Hawaiian Islands, characterized as coastal bodies of land-locked salt or brackish water that fluctuate with the tides due to subterranean connections, are the only ecosystems of this type found within the United States. These habitats are currently subject to anthropogenic impacts that threaten their future existence. Previous research has shown strong genetic population structure of an endemic atyid shrimp, Halocaridina rubra, in these habitats. The native alpheid shrimp, Metabetaeus lohena, whose known range entirely overlaps that of $H$. rubra, has feeding and reproductive behaviors that are biologically distinct from H. rubra. Its historic scarcity and status as a candidate for the US Fish and Wildlife Department's Endangered Species List, make $M$. lohena an ideal species to compare against the known genetic structure of $H$. rubra. We investigated the population structure of this native anchialine shrimp to test the hypothesis that genetic population structure differs between the two shrimp species and that $M$. lohena is genetically unstructured across its range. A survey of $605 \mathrm{bp}$ of the mitochondrial cytochrome c oxidase subunit I (COI) gene from 127 individuals collected at 7 sites spanning the islands of O'ahu, Maui and Hawaii revealed 43 haplotypes. The most common haplotype was represented in similar proportions from all sites sampled, accounting for $44 \%$ of the surveyed sequences. Analyses of molecular variation (AMOVA), pairwise $\Phi_{\mathrm{ST}}$ values, Bayesian estimates of migration $(M)$, Mantel tests and Nested Clade Analyses (NCAs) all failed to reveal evidence of major barriers to gene flow among most populations separated by inter-island channels. This lack of genetic structure in M. lohena is found to be in stark contrast with the highly structured population of $H$. rubra, and may be attributed to oceanic dispersal strategies and/or a recent introduction to the Hawaiian Islands. Rev. Biol. Trop. 58 (1): 159-170. Epub 2010 March 01.
\end{abstract}

Key words: anchialine, Metabetaeus lohena, shrimp, COI, gene flow, Hawaii.

The varied life history traits of aquatic organisms have profound impacts on their distribution, ecology and evolution. It follows that dispersal ability of aquatic organisms in coastal wetland habitats can be a strong determinant of population connectivity and evolutionary diversification. For organisms with larval development, duration of larval planktonic period governed by feeding modes (among other factors) is expected to correlate with dispersal ability where planktonic dispersal is necessary to span gaps between habitats. There is an established body of evidence linking larval feeding strategies and genetic connectivity among aquatic organisms (Strathman 1985, Palumbi 1994, 1995, Emlet 1995, Bohonak 1999, Jeffrey \& Emlet 2003). Although exceptions to this pattern can be found in many taxa 
(e.g., Barber et al. 2002, Bowen et al. 2006, Miller \& Ayre 2008), wide dispersal and low genetic differentiation are predicted for organisms that produce planktotrophic larvae while trends of low dispersal and extensive differentiation by distance are expected for those with lecithotrophic larvae.

Anchialine pools are coastal wetlands that display tidal fluctuations despite lacking surface connections to the ocean (Holthius 1973). Their wide salinity ranges and tidal oscillations indicate the presence of subsurface connections to both the freshwater aquifer and the ocean. The habitat ranges in morphology from exposed pools in recent lava formations to limestone sinkholes and underground aquatic cave systems (Maciolek 1983, Brock et al. 1987). Anchialine pools exist worldwide, in areas such as the Sinai Peninsula, Madagascar, Europe, Japan, Bermuda, Yucatan Peninsula, Australia and many sites in the tropical Pacific (Maciolek 1983, Brock 1985, Sket 1996, Iliffe 2000, Page et al. 2008). The only anchialine habitats known within the United States are in the Hawaiian Islands, specifically restricted to the islands of O'ahu, Maui, Moloka'i, Hawaii and Kaho'olawe (Brock 1985, Bailey-Brock \& Brock 1993, Brock \& Bailey-Brock 1998). These habitats are becoming increasingly rare and currently face multiple impacts due to anthropogenic activities. While conservation of these systems is a topic of extreme interest in the Hawaiian Islands, little is known about the ecological and evolutionary forces operating on organisms from these habitats.

Recent studies examining the population genetics of endemic anchialine organisms report discrepant findings. For example, two atyid shrimp, Typhylata illiffei and Typhylata mitchelli (Decapoda, Atyidae) from anchialine cenotes of the Yucatan, have low nucleotide divergence between populations of different cave systems, indicating gene flow over long distances (Hunter et al. 2007). Likewise, population panmixia was found for a gastropod, Neritilia granosa, in anchialine caves separated by $200 \mathrm{~km}$ of sea in the Philippines (Kano \& Kase 2004). On the other hand, Halocaridina rubra, an atyid endemic to anchialine habitats in the Hawaiian Islands, has extremely low levels of gene flow between populations at limited (i.e., $<35 \mathrm{~km}$ ) geographic scales (Santos 2006, Craft et al. 2008). In this context, it has been proposed that life history traits (such as larval feeding mode) significantly impact the population structure, ecology, and evolution of anchialine organisms (Kano \& Kase 2004, Craft et al. 2008). To assess this, however, requires the study of additional anchialine species.

Some of the commonly known organisms from anchialine habitats in Hawaii are a number of red-pigmented shrimp species. The most abundant of these are Halocaridina rubra and Metabetaeus lohena (Banner \& Banner 1960). The latter species, which grows to $18 \mathrm{~mm}$, is an alpheid scavenger and predator of $\mathrm{H}$. rubra as well as other small anchialine invertebrates (Holthius 1973, Brock 2004). In 1989, M. lohe$n a$ was petitioned as a candidate for the United States Fish and Wildlife Service's Endangered Species List due to increasing scarcity and impending threats to its habitat. While little is known about its reproduction, gravid females with masses of 20-29 eggs are commonly observed in the wild. Additionally, attempts to propagate $M$. lohena and $H$. rubra in captivity identified distinct differences between the species. Specifically, larvae of $M$. lohena lack a yolk sac (T. Iwai unpublished), suggesting that this species utilizes a planktotrophic larval feeding mode. In contrast, $H$. rubra produces larvae with a yolk sac (i.e., lecithotrophic: Couret \& Wong 1978, Bailey-Brock \& Brock 1993, Iwai 2005). Thus, the contrasting larval feeding strategy, shared habitat and distribution, as well as candidate endangered status of $M$. lohena makes it an ideal species to compare against the known genetic structure of $H$. rubra. Furthermore, having information on the population structure of these two species will prove useful when evaluating protection or mitigation options for specific Hawaiian anchialine habitats that are threatened by anthropogenic effects.

In this study, we examined the genetic variation and population structure of M. lohena 
in the Hawaiian Islands. Given that M. lohena produces planktotrophic larvae putatively capable of dispersing long distances, we hypothesized that the species would exhibit little to no population structure among anchialine habitats in the Hawaiian Islands. To test this, individuals of $M$. lohena were collected across their known range and sequences of the mitochondrial cytochrome oxidase I (COI) gene were compared to elucidate population structure and infer gene flow among geographically disparate anchialine habitats on and between each island. We found that the population structure of $M$. lohena does contrast with previous work on H. rubra (Santos 2006, Craft et al. 2008), thus providing insight into how variation in life history traits can have disparate consequences for two interdependent decapods specialized to the same unique habitat.

\section{MATERIALS AND METHODS}

Collection of Biological Materials: Individuals of Metabetaeus lohena were collected from seven anchialine pools on Hawai' i, Maui, and $\mathrm{O}$ 'ahu (Fig. 1) between June 2005 and March 2006. Collections were done with small baited traps and/or a baited hand net. The small sample sizes at particular locations reflect the rarity of this species within specific pools. Whole shrimp were preserved in $95 \% \mathrm{EtOH}$ and held at $-20{ }^{\circ} \mathrm{C}$ in the lab until processed.

Molecular Methods: Total genomic DNA was extracted from each individual using the DNeasy Tissue Kit (QIAGEN). Briefly, heads were removed with a clean razor blade, ground in QIAGEN ATL Buffer, and incubated overnight with Proteinase $\mathrm{K}$ at $55^{\circ} \mathrm{C}$. Remaining steps were performed as described in the manufacturer's protocol. The primers LCO-1490 (5'-GGT CAA CAA ATC ATA AAG ATA TTG G-3') and HCO-2198 (5'-TAA ACT TCA GGG TGA CCA AAA AAT CA-3') (Folmer et al. 1994) were used to amplify a $658 \mathrm{bp}$ fragment of the COI gene from the mitochondrial genome. Amplifications were carried out in $50 \mu \mathrm{L}$ volume reactions with 100-400ng of genomic

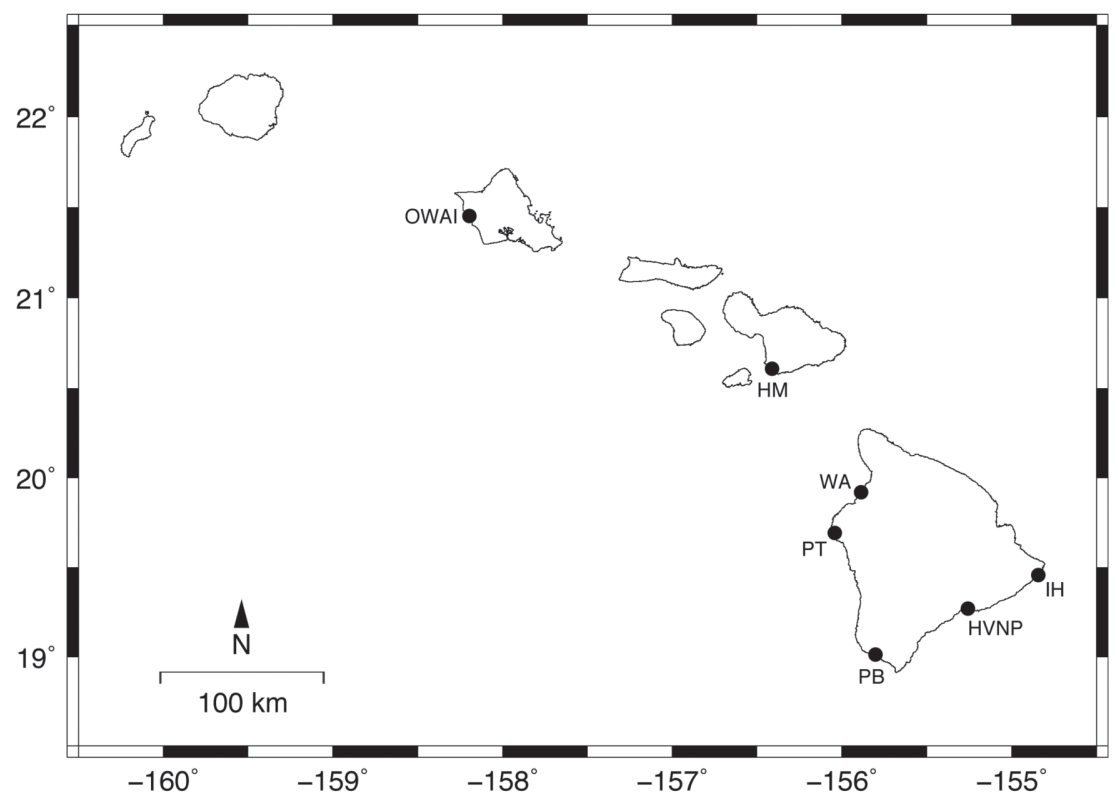

Fig. 1. Hawaiian Islands; collection sites in this study: Wai'anae Sinkhole (OWAI: 21.45, -158.20). La Perouse Bay (HM: 20.61, -156.41) Hawaii Volcanoes National Park (HVNP: 19.27, -155.26) Pohue Bay (PB:19.01, -155.80) Waikoloa (WA: 19.92, -155.89) Pine Trees (PT: 19.69, -156.04) Isaac Hale (IH:19.46, -154.84). Individuals sampled per location: OWAI (7), HM (19), WA (21), PT (20), PB (20), HVNP (20), IH (19). 
template, $10 \mathrm{mM}$ Tris- $\mathrm{HCl}(\mathrm{pH} 8.3), 50 \mathrm{mM}$ $\mathrm{KCl}, 2.0 \mathrm{mM} \mathrm{MgCl} 2,200 \mu \mathrm{M}$ dNTPs, $400 \mathrm{nM}$ of each primer, and $1 \mathrm{U}$ Taq DNA polymerase (Eppendorf). DNA was initially denatured at 94 ${ }^{\circ} \mathrm{C}$ for $5 \mathrm{~min}$, then 15 cycles of $95^{\circ} \mathrm{C}$ denaturing for $45 \mathrm{~s}, 40^{\circ} \mathrm{C}$ annealing for $45 \mathrm{~s}$, and $72^{\circ} \mathrm{C}$ extension for $1 \mathrm{~min}$. The annealing temperature was then raised to $55^{\circ} \mathrm{C}$ for another 25 cycles with denaturing and extension temperatures as before. The program ended with a final extension of $72^{\circ} \mathrm{C}$ for $5 \mathrm{~min}$.

Amplicons were cleaned with a QIAquick Spin Miniprep Kit (QIAGEN) following the manufacturer's protocol. Nested primers, FLCON (5'-GCA TGA TCA GGT ATG GTA GGG -3') and RLCON (5'-TAA GTG YTG ATA GAG GAC CGG -3') were designed for use in sequencing. Sequencing reactions (ABI PRISM $^{\text {TM }}$ BigDye $^{\mathrm{TM}}$ v3.0 Terminator Cycle Sequencing Ready Reaction Kit) were carried out in a $10 \mu \mathrm{L}$ volume reaction containing $2 \mu \mathrm{L}$ of Terminator Ready Reaction Mix, $2 \mu \mathrm{L}$ of Sequencing Buffer, 100ng of PCR product, and $5 \mathrm{pmol}$ of primer brought to volume with nuclease free water. The cycle sequencing program consisted of an initial step at $94^{\circ} \mathrm{C}$ for $3 \mathrm{~min}$, 30 cycles of $96^{\circ} \mathrm{C}$ for $20 \mathrm{~s}, 50^{\circ} \mathrm{C}$ for $20 \mathrm{~s}$, and $60^{\circ} \mathrm{C}$ for $4 \mathrm{~min}$. Both heavy and light strands were sequenced from each individual. The BigDye labeled products were cleaned with the Clean SEQ kit (Agencourt Bioscience), utilizing magnetic beads to selectively capture sequencing products. Sequencing products were separated by electrophoresis and analyzed using an automated ABI 3730 XL Genetic Analyzer. Forward and reverse sequences were trimmed and verified by eye against the chromatograms and aligned with BioEdit v7.0 (Hall 1999). This resulted in $605 \mathrm{bp}$ of sequence from 127 individuals being utilized in subsequent analyses.

Genetic Diversity and Population Structure Analyses: Total number of haplotypes, as well as number of haplotypes, haplotype diversity $(h)$ and nucleotide diversity $(\pi)$ for each sample site, were calculated using the program Arlequin v3.1 (Excoffier et al. 2006). Overall nucleotide diversity and average number of differences were calculated in DnaSP v4.06 (Rozas et al. 2003). Nucleotide sequences were translated using the invertebrate mitochondrial code in BioEdit and amino acid sequences were examined for nonsynonymous amino acid changes, which are potentially indicative of "COI-like" pseudogenes being present in the data (Buhay 2009).

Genetic variation within and among subpopulations was determined using an Analysis of Molecular Variance (AMOVA) in Arlequin v3.1. For this study, we estimated the contribution of molecular variance at three levels: (a) among islands $\left(\Phi_{\mathrm{CT}}\right)$, (b) among subpopulations on an island $\left(\Phi_{\mathrm{SC}}\right)$ and (c) within each subpopulation $\left(\Phi_{\mathrm{ST}}\right)$. Tamura \& Nei's (1993) model of evolution was used to calculate pairwise $\Phi_{\mathrm{ST}}$ statistics and AMOVA values and their significance assessed by 1000 permutations. Using an iteration of the formula, $\mathrm{F}_{\mathrm{ST}}=1 /$ $\left(1+4 N_{m}\right)$ where $N_{m}$, the product of the migration rate $(m)$ and effective population size $\left(N_{e}\right)$, equals an estimate of the number of reproductively successful female migrants per generation, the number of migrating individuals $\left(N_{m}\right)$ was calculated for each pairwise subpopulation comparison of $\Phi_{\mathrm{ST}}$ (Wright 1978, Slatkin 1991, Waples 1998).

To differentiate between effects of ongoing migration $\left(M=2 N_{e f} m\right)$ and recent divergence between subpopulations, migration rates per generation between select pairs of populations were calculated using the program MDIV (available at http://cbsuapps.tc.cornell.edu/). This program uses the Markov Chain Monte Carlo (MCMC) method described by Nielsen \& Wakeley (2001) to distinguish between current migration and the lingering effects of historical association as possible explanations for population similarity. Three independent runs, assuming the HKY finite sites model, with different random seeds, were performed. For each run, parameters were set as follows: $M_{\max }=50, T_{\max }=10$, length of Markov chain = 2000000 steps, burn in time 500000 cycles. The results from three independent runs for $M$ were graphed against posterior probabilities 
and estimates with the highest posterior probabilities were accepted as the best estimates of migration per generation. Once defined, values of $M$ between populations were compared to the $N_{m}$ values derived from the $\Phi_{\mathrm{ST}}$.

Demographic and Network Analyses: A Mantel test (Mantel 1967) was implemented in the program Alleles In Space (AIS) (Miller $2005)$ with 1000 permutations $(\alpha=0.05)$ to test for isolation by distance through correlations between matrices of pairwise genetic distances $\left(\mathrm{F}^{\mathrm{st}} /\left(1-\mathrm{F}^{\mathrm{st}}\right)\right.$ and geographical distances between subpopulations (Rousset 1997). Tajima's $D$ (1989) and Fu's $F_{s}$ statistics (Fu \& Li 1993, $\mathrm{Fu}$ 1997) were conducted in Arlequin v3.1 to assess whether the COI sequence variations of $M$. lohena significantly differed from that expected under neutral conditions. While neutrality tests are most commonly used to detect the influence of selection, they can also be potentially informative about the demographic forces that have affected a population (Tajima 1989, Fu 1997). Significance of these neutrality tests was determined by 1000 permutations.

To visualize the relationships among $M$. lohena $\mathrm{COI}$ haplotypes, a statistical parsimony network with a confidence level of $95 \%$ was constructed using the program TCS v1.21 (Clement et al. 2000). Ambiguous connections, represented by reticulations in the network, were resolved according to the criteria recommended by Crandall et al. (1994). The resulting network was then used to construct a nested clade design according to the procedure in Templeton et al. (1998). From the nested cladogram and geographic coordinates of the sampling sites, a matrix defining genetic and geographical distances was created and analyzed via exact permutation contingency analysis in GEODIS v2.4 (Posada et al. 2000, 2006). The statistical significance of $D_{c}$ (i.e., clade distance) and $D_{n}$ (i.e., nested clade distance) was determined by 10000 permutations for testing the null hypothesis of no geographical association within the nested design (Templeton et al. 1995, Posada et al. 2006). Significant values of $D_{c}$ and $D_{n}$ were interpreted for biological significance using the November 2005 NCA inference key (available at http:// darwin.uvigo.es/).

\section{RESULTS}

\section{Genetic Diversity and Population Struc-} ture: A total of 43 distinct COI haplotypes were identified from the 127 Metabetaeus lohena individuals examined in this study. Of these, seven haplotypes were sampled more than once while the remaining 36 occurred as singletons. In all, $41(6.7 \%)$ nucleotide positions were variable (though no single haplotype had all single nucleotide polymorphisms) and the average number of differences between any two sequences $(k)$ was 1.481 . The nucleotide diversity of the entire Hawaiian population was $\varpi=0.00246$. While the majority of substitutions were synonymous or 'silent', not resulting in an amino acid change, two of the 41 were nonsynonymous in nature, resulting in amino acid substitutions. However, these substitutions were to chemically similar amino acids, suggesting that they do not represent "COI-like" pseudogenes (Buhay 2009). Within each subpopulation, the number of haplotypes ranged between 5-14, though the sample size from O'ahu ( $\mathrm{n}=7$ ) was considerably smaller than that of the other sites. Mean number of pairwise differences $(\pi)$ and haplotype $(h)$ diversity are summarized in Table 1. Sequences were deposited into GenBank under Accession Numbers GU228388-GU228430.

The AMOVA found a majority of the observed genetic variation in $M$. lohena occurring within individual populations $(95.14 \%$, $\left.\Phi_{\mathrm{ST}}=0.021, \mathrm{p}<0.01\right)$, while variation among populations explained the remainder $(4.86 \%$, $\Phi_{\mathrm{SC}}=0.049, \mathrm{p}<0.01$ ) (Table 2). None of the total variance was explained among islands $\left(\Phi_{\mathrm{CT}}\right.$, Table 2$)$. Pairwise $\Phi_{\mathrm{ST}}$ values were significant for 6 of the 21 population comparisons at $\mathrm{p}<0.05$, while one pairwise $\Phi_{\mathrm{ST}}$ value was significant at $\mathrm{p}<0.001$ (Table 3). Pairwise comparisons of genetic structure between O'ahu and Halape and Pohoiki and Halape produced $\Phi_{\mathrm{ST}}$ values of 0.16164 and 0.16165 
TABLE 1

Sample size and descriptive statistics for mitochondrial cytochrome oxidase I (COI) data from the 127 Metabetaeus lohena included in the study

$\begin{array}{ccccccc}\text { Site } & \mathrm{n} & \mathrm{nh} & \prod & \mathrm{h} & \text { Tajima's D } & \text { Fu's F }_{\text {s }} \\ \text { WA } & 21 & 11 & 0.0028(0.0018) & .7810(.0943) & -2.17^{*} & -6.86^{*} \\ \text { PB } & 20 & 10 & 0.0026(0.0018) & .8316(.0751) & -1.63^{*} & -5.26^{*} \\ \text { IH } & 21 & 9 & 0.0021(0.0015) & .7238(.1011) & -1.61^{*} & -5.08^{*} \\ \text { PT } & 20 & 14 & 0.0032(0.0021) & .9158(.0546) & -2.11^{*} & -12.04^{*} \\ \text { HVNP } & 19 & 5 & 0.0017(0.0013) & .6667(.0744) & -0.847 & -1.08 \\ \text { HM } & 19 & 6 & 0.0014(0.0011) & .6550(.1115) & -0.73 & -2.83^{*} \\ \text { OWAI } & 7 & 5 & 0.0028(0.0021) & .8571(.1371) & -1.52^{*} & -1.89\end{array}$

TABLE 2

Analysis of molecular variance (AMOVA) for populations of Metabetaeus lohena across the Hawaiian Islands

\begin{tabular}{|c|c|c|c|c|c|}
\hline Source of variation & d.f. & $\begin{array}{l}\text { Sum of } \\
\text { squares }\end{array}$ & $\begin{array}{l}\text { Variance } \\
\text { component }\end{array}$ & $\%$ variation & $\Phi$ statistic \\
\hline Among islands & 2 & 1.513 & $-0.021 \mathrm{Va}$ & 0 & $\Phi_{\mathrm{CT}}=-0.028$ \\
\hline $\begin{array}{l}\text { Among subpopulations within } \\
\text { islands }\end{array}$ & 4 & 5.818 & $0.036 \mathrm{Vb}$ & 4.86 & $\Phi_{\mathrm{SC}}=0.049 *$ \\
\hline Within subpopulations & 120 & 85.953 & $0.716 \mathrm{Vc}$ & 95.14 & $\Phi_{\mathrm{ST}}=0.022 *$ \\
\hline Total & 126 & 93.283 & 0.732 & & \\
\hline
\end{tabular}

$\mathrm{Va}, \mathrm{Vb}$, and $\mathrm{Vc}$ are the associated covariance components. $*=\mathrm{p}<0.01$.

TABLE 3

Pairwise $\Phi_{S T}$ values (lower triangle) as measures of variation among populations of Metabetaeus lohena across the Hawaiian Islands

$\begin{array}{cccccccc} & \text { OWAI } & \text { HM } & \text { WA } & \text { PT } & \text { PB } & \text { HVNP } & \text { IH } \\ \text { OWAI } & & 0.06452 & 0.54245 & 0.76217 & 0.25563 & 0.01267 & 0.20321 \\ \text { HM } & 0.06653 & & 0.17702 & 0.12974 & 0.53065 & 0.07125 & 0.06665 \\ \text { WA } & -0.00685 & 0.01215 & & 0.39581 & 0.78015 & 0.01021 & 0.02541 \\ \text { PT } & -0.01645 & 0.01837 & 0.00273 & & 0.13172 & 0.00335 & 0.07408 \\ \text { PB } & 0.01580 & -0.00579 & -0.01192 & 0.01580 & & 0.21271 & 0.05280 \\ \text { HVNP } & 0.16154^{*} & 0.07282 & 0.07766^{*} & 0.10427^{*} & 0.01736 & & 0.00000 \\ \text { IH } & 0.03326 & 0.03906 & 0.03455^{*} & 0.02336 & 0.03491^{*} & 0.16164^{* *} & \end{array}$

$* \mathrm{p}<0.05, * * \mathrm{p}<0.001 p$ values (upper triangle) calculated for each pairwise comparison.

respectively. According to the generalization by Wright, those values correspond to moderate genetic variation between these populations and translates to a migration estimate $\left(N_{m}\right)$ of 1.29 individuals per generation. Translation of the remaining significant $\Phi_{\mathrm{ST}}$ pairwise comparisons revealed values of $N_{m}>2.0$ (Table 4 ), suggesting appreciable levels of gene flow is occurring between sites.

Similar trends of migration to those of the pairwise $\Phi_{\mathrm{ST}}$ analysis were detected by the MDIV coalescent method (Table 4). In this 
TABLE 4

Migration estimates based on $N_{m}$ (calculated from $\Phi_{S T}$ ) and $M$ (calculated from a coalescent model) for populations of Metabetaeus lohena across the Hawaiian Islands.

$\begin{array}{cccc}\text { Significant } \Phi_{\mathrm{ST}} & \text { Pairwise population comparison } & \mathrm{N}_{\mathrm{m}} & \mathrm{M} \\ 0.16164 & \text { OWAI-HVNP } & 1.29 & 0.7 \\ 0.16165 & \text { IH-HVNP } & 1.29 & 1.1 \\ 0.07766 & \text { WA-HVNP } & 2.96 & \text { NS } \\ 0.10427 & \text { PT-IH } & 2.14 & 2.7 \\ 0.03455 & \text { WA-IH } & 6.99 & \text { NS } \\ 0.03491 & \text { IH-PB } & 6.91 & \text { NS }\end{array}$

$\mathrm{NS}=$ data insufficient to estimate $\mathrm{M}, \mathrm{M}>50$. Comparisons are limited to pairwise populations exhibiting significant differentiation.

case, $M$ was estimated confidently for comparisons of O'ahu and Halape $(M=0.7)$, Pohoiki and Halape $(M=1.1)$, Pine Trees and Halape $(M$ $=2.7)$, and Maui and O'ahu $(M=1.4)$. For most other comparisons, the data were insufficient to estimate migration rates since the analyses resulted either in a plateau or a continual rise in the estimates of $M$. Because small values of $M$ can be excluded due to their extremely low likelihood scores, this implies that $M$ is greater than 50 individuals per generation, the limit at which the analyses were performed (Rivera et al. 2003, Santos 2006).

\section{Demographic and Network Analyses:} The Mantel test revealed no significant correlation between pairwise genetic distance and geographic distance $(r=0.02)$. Significantly negative values $(\mathrm{p}<0.05$, Table 1$)$ of Tajima's $D$ were found for most populations, with the exception of Halape and Maui. Additionally, most populations had significant and large negative Fu's $F_{s}$ values $(\mathrm{p}<0.02$, Table 1$)$. Taken together, this suggests that nearly all of the M. lohena populations have undergone recent population expansions.

A single network was recovered from the statistical parsimony analysis of $M$. lohena, encompassing individuals from all seven sites across the three islands (Fig. 2). All populations shared the most common COI haplotype, which accounted for $44 \%$ (56 of 127) of the recovered sequences. None of the shared haplotypes were geographically restricted, a pattern consistent with high levels of gene flow or recent geographical expansion. For the NCA, associations between genetic and geographic distribution were rejected for most step-1 clades. Only two significant clades (e.g., 1-6 and 2-3) were identified in the analysis, with isolation by distance being suggested for clade 1-6 and no conclusive outcome due to sampling strategy for clade 2-3 (Fig. 2).

\section{DISCUSSION}

Based on a variety of statistical analyses and consistent with our hypothesis, we found an overall lack of demonstrable population structure in the anchialine alpheid shrimp, $M$. lohena, across the Hawaiian Islands. Overall, $M$. lohena appears to have a high level of gene flow with occasional instances of isolation by distance, as indicated by a few significant pairwise $\Phi_{\mathrm{ST}}$ values between anchialine habitats. This conclusion is further supported by global AMOVA values and estimates of migration $(M)$ based on a coalescent method. Though Nested Clade Analyses revealed two statistically significant clades, this significance may be attributed to stochasticity and low sample size at OWAI (Wai'anae Sinkhole). Of the two significant clades identified (clade 1-6 and clade 2-3, Fig. 2), haplotypes from all habitats sampled were represented in clade $1-6$, and 

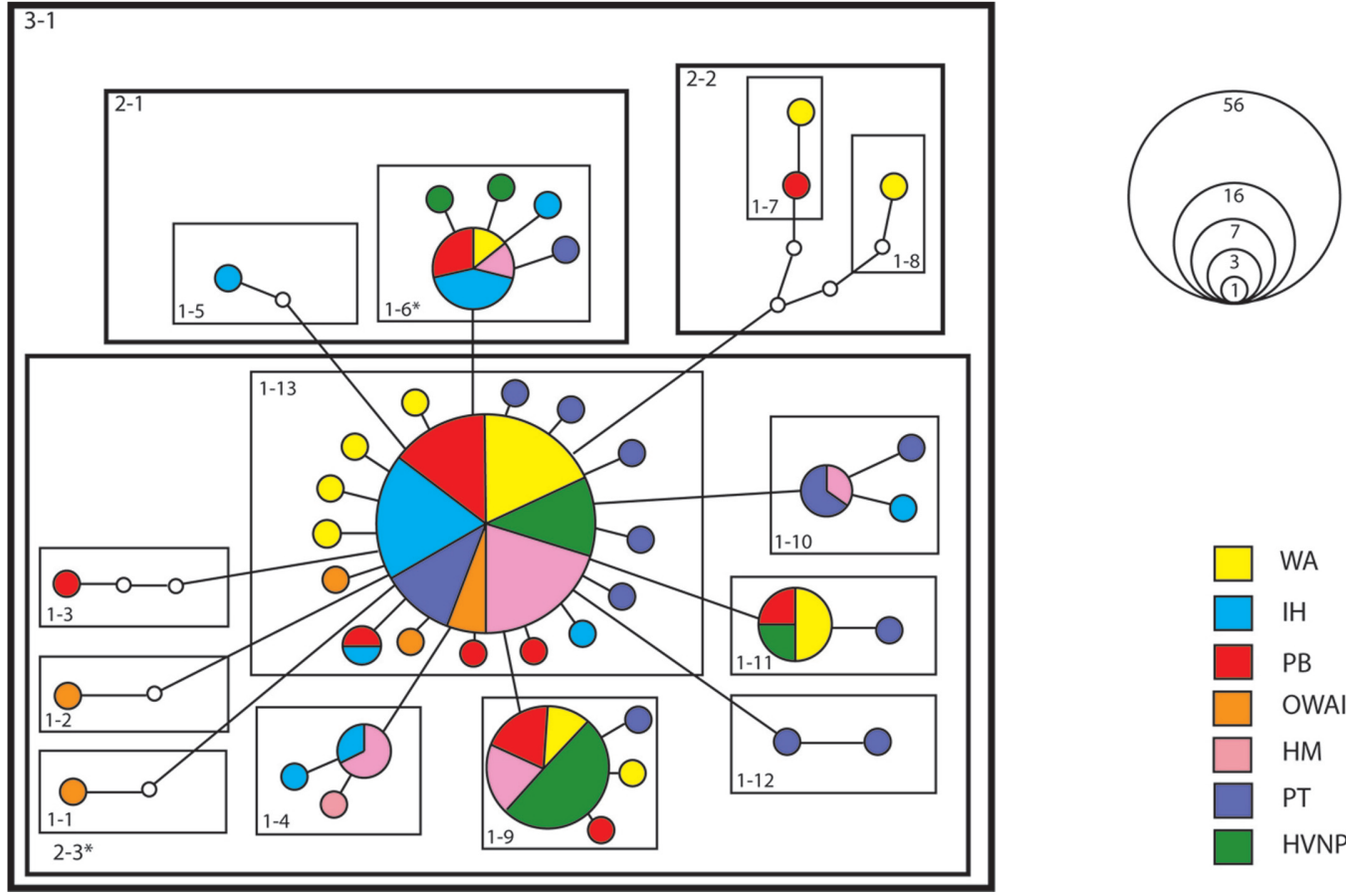

Fig. 2. Haplotype network depicting the nesting levels used to infer meaning behind phylogeographic significance in Metabetaeus lohena populations in the Hawaiian Islands. Statistically significant clades marked with an asterisk. Sampled haplotypes are indicated by colored circles or portions thereof while black dots represent unsampled (missing) haplotypes. The size of a circle is proportional to the frequency at which a haplotype was recovered. Color codes for each collection location are presented in the legend.

all of the OWAI haplotypes were represented within clade 2-3. Due to the heavily impacted habitat at the OWAI location that we observed to have dramatic effects on the population size, only 7 individuals could be collected within a reasonable amount of time.

Despite geographic isolation of anchialine habitats by expanses of ocean or aquifer compartmentalization (Santos 2006), the more-orless homogenous distribution of $M$. lohena $\mathrm{COI}$ haplotypes implies a general absence of isolating barriers, thus leading to panmixia between populations. Notably, the genetic structure of M. lohena in Hawaii contrasts sharply with that of the atyid H. rubra (Santos 2006, Craft et al. 2008) from these same habitats. It has been previously proposed that the life history traits of anchialine organisms significantly impact their population structure, ecology, and evolution (Kano \& Kase 2004, Craft et al. 2008). Specifically in this case, M. lohena and $H$. rubra have different larval feeding strategies (see Introduction), which may impede (i.e., H. rubra) or enable (i.e., M. lohena) dispersal among anchialine habitats on and between islands, consistent with the highly structured populations of H. rubra (Craft et al. 2008) and the negligible population structure of $M$. lohena observed here.

Anchialine habitats in the Hawaiian Islands face growing threats from development, invasive species and groundwater extraction and contamination. If the observed lack of genetic structure is indeed a result of a high degree of dispersal, it is enticing to assume that $M$. lohena may be resilient to local extirpation 
and capable of colonizing available anchialine habitats (whether man-made or natural) relatively quickly. Although the lowest estimates of migration calculated between distant habitats (i.e., 1-7 individuals) are sufficient to keep genetic structure to a minimum, one must remember that $N_{m}$ is derived using island model assumptions (Wright 1943) that are often violated in natural populations. This also applies to Bayesian estimates of $M$, which assume equal population sizes that do not change over time (Nielsen \& Wakeley 2001). It has been shown in marine species that as gene flow increases, the signal to noise ratio decreases and the ability of many models to predict accurate migration diminishes in turn (Waples 1998). Likewise, any detectable level of genetic structuring can be indicative of extremely limited actual dispersal (Palumbi 2003). Additionally, even if a species has high dispersal potential, other barriers to gene flow can prevent colonization of available habitats. Given the limited knowledge on the basic biology of $M$. lohena and the unknown effects that factors such as geohydrology, prevailing currents, and predation may have on its ability to disperse, it remains unclear whether the estimates of migration reported here are ample to predict successful colonization of new anchialine habitats on ecological timescales.

Nucleotide diversity within $M$. lohena and $H$. rubra is highly different, with pairwise distances between any two haplotypes ranging between $0.16-6.9 \%$ for $H$. rubra (Craft et al. 2008 ) and $0.17-1.16 \%$ for M. lohena. Due to the low level of divergence within $M$. lohena and the finding that the species has undergone recent expansion, it cannot be ruled out that the observed genetic variation is a reflection of a recent colonization of the Hawaiian Islands. Population structure is a consequence of past and present effects that can be difficult to tease apart (e.g., Templeton 1998, Nielsen \& Slatkin 2000). If the colonization is indeed recent, selective sweep acting on a locus linked to COI in this species could explain these low diversity values (Maynard-Smith \& Haigh 1974). A survey of microsatellites in this population could provide higher resolution data to investigate genetic association among habitats.

The similar distribution of shared haplotypes across all of the sampled habitats indicates that no single anchialine habitat contains a unique assemblage of $M$. lohena genotypes. While the genetic diversity in the metapopulation is relatively low, the large number of sequence singletons implies an expanding population rather than a declining one. However, in spite of its potential resilience due to evidence of varying levels of gene flow among populations, human development and other anthropogenic factors may still severely and negatively impact $M$. lohena over its natural range. This is particularly true since the species has only been observed in anchialine habitats free of invasive species. Although the lack of genetic structure in $M$. lohena reported here does not present a strong argument for the endangered candidacy of this species, with consideration for the caveats outlined above, it is clear that much remains to be eludicated with regards to its basic biology, ecology, and evolution. The increasing rarity of pristine anchialine environments in Hawaii (Brock 2004) underscores the importance of preserving $M$. lohena dispersal pathways by maintaining a diverse spectrum of habitats to support sustainable populations of anchialine organisms throughout the Hawaiian Islands.

\section{ACKNOWLEDGMENTS}

We gratefully thank Robert Nishimoto, Tom Iwai, Mike N.Yamamoto, and John N. Kahiapo of the Hawaii Division of Aquatic Resources, David Foote of United States Geological Survey, David Chai of Hualalai Resorts, Bill Gilmartin of Hawaii Wildlife Fund, Vern Yamanaka of Pohue Bay, Matt Craig of University of Hawaii at Manoa, Hawaii Volcanoes National Park, Sharon Zeigler-Chong, and Charlie Chong for their assistance. We also thank the three anonymous reviewers whose valuable comments improved this work.

Funding for this work was provided by the National Science Foundation EPSCoR and by 
the Hawaii Division of Aquatic Resources of the Hawaii Department of Land and Natural Resources.

\section{RESUMEN}

Los hábitats de los alfeidos de las islas de Hawaii, se caracterizan por ser zonas cerradas de aguas saladas o salobres, que fluctúan con las mareas, debido a las conexiones subterráneas, son los únicos ecosistemas de este tipo que se encuentran en Estados Unidos. Estos hábitats actualmente están sujetos a impactos antropogénicos que amenazan su existencia futura. La investigación anterior ha demostrado una fuerte estructura genética de una población de camarones atíidos endémicos, Halocaridina rubra, en estos hábitats. El camarón alfeido nativo, Metabetaeus lohena, cuya área de distribución conocida se superpone totalmente con la de $H$. rubra, tiene comportamientos alimenticios y reproductivos que son biológicamente diferentes a los de H. rubra. Su escasez histórica y su condición de candidato para aparecer en la Lista de Especies en Peligro del Departamento de Pesca y Vida Silvestre de Estados Unidos, hace de $M$. lohena una especie ideal para comparar su estructura genética con la de H. rubra. Se investigó la estructura de la población de este camarón alfeido nativo para probar la hipótesis que la estructura genética de la población difiere entre las dos especies y que la de $M$. lohena está genéticamente no estructurada en todo su ámbito. El análisis de 605 pb de la oxidasa mitocondrial citocromo c subunidad I (COI) de genes de 127 individuos recolectados en 7 sitios que abarcan las islas de Oahu, Maui y Hawaii reveló 43 haplotipos. El haplotipo más común fue representado en proporciones similares en todos los sitios incluidos en la muestra, de acuerdo al $44 \%$ de las secuencias estudiadas. El análisis de variación molecular (AMOVA), los valores de $\Phi_{\mathrm{ST}}$ pareados, la estimación bayesiana de la migración (M), las pruebas de Mantel y los Análisis Cladísticos no pudieron revelar la existencia de importantes barreras al flujo genético entre las poblaciones más separadas por los canales entre las islas. La falta de estructura genética en $M$. lohena contrasta con la muy estructurada población de $H$. rubra, y puede ser atribuida a las estrategias de dispersión oceánica y/o una introducción reciente en las islas hawaianas.

\section{REFERENCES}

Bailey-Brock, J.H. \& R.E. Brock. 1993. Feeding, reproduction, and sense organs of the Hawaiian anchialine shrimp Halocaridina rubra (Atyidae). Pac. Sci. 47: 338-355.

Banner, A.H. \& D.M. Banner. 1960. Contributions to the knowledge of shrimp of the Pacific Ocean. Part VII.
On Metabetaeus Borradaile, species from Hawaii. Pac. Sci. 14: 299-303.

Barber, P.H., S.R. Palumbi, M.V. Erdmann \& M.K. Moosa. 2002. Sharp genetics breaks among populations of Haptosquilla pulchella (Stomatopoda) indicate limits to larval transport: patterns, causes, and consequences. Mol. Ecol. 11:659-674.

Bohonak, A.J. 1999. Dispersal, gene flow, and population structure. Q. Rev. Biol. 74: 21-43.

Bowen, B.W., A.L. Bass, A.J. Muss, J. Carlin \& D.R. Robertson. 2006. Phylogeography of two Atlantic squirrelfishes (family Holocentridae): Exploring pelagic larval duration and population connectivity. Mar. Biol. 149:899-913.

Brock, R.E. \& J.H. Bailey-Brock. 1998. A unique anchialine pool in the Hawaiian Islands. Int. Rev. Hydrobiol. 83: 65-75.

Brock, R.E. 2004. Anchialine resources in two Hawaii state Natural Area Reserves: Ahihi Kina'u, Maui Island and Manuka, Hawaii Island with recommendations for their management. Environmental Assessment LLC, Honolulu, Hawaii, USA.

Brock, R.E., J.E. Norris, D.A. Ziemann \& M.T. Lee. 1987. Characteristics of water quality in anchialine ponds of the Kona, Hawaii, coast. Pac. Sci. 41: 200-208.

Brock, R.E. 1985. An assessment of the condition and future of the anchialine pond resources of the Hawaiian Islands. In US Army Corps of Engineers, Honolulu District Final Environmental Impact Statement US Department of the Army Permit Application, Waikoloa Beach Resort. Waikoloa, Hawaii, USA.

Buhay, J.E. 2009. "COI-like" sequences are becoming problematic in molecular systematics and DNA barcoding studies. J. Crust. Biol. 29: 96-110.

Clement, M., D. Posada \& K.A. Crandall. 2000. TCS: a computer program to estimate gene genealogies. Mol. Ecol. 9: 1657-1659.

Couret, C.L. \& D. Wong. 1978. Larval development of the Halocaridina rubra Holthius (Decapoda, Atyidae). Crustaceana 34: 301-309.

Craft, J.D., A. Russ, M.N. Yamamoto, T.Y. Iwai, S. Hau, J. Kahiapo, C.T. Chong, S. Zeigler-Chong, C. Muir, Y. Fujita, D.A. Polhemus, R.A. Kinzie \& S.A. Santos. 2008. Islands under islands: The phylogeography and evolution of Halocaridina rubra Holthuis, 1963 (Crustacean: Decapoda: Atyidae) in the Hawaiian archipelago. Limn. Ocean. 53: 675-689. 
Crandall, K.A., A.R. Templeton \& C.F. Sing. 1994. Intraspecific cladogram estimation: problems and solutions, p. 273-297. In P.H. Harvey, A.J.L. Brown, J.M. Smith, and S. Nee (eds.). New uses for new phylogenies. Oxford Press, Oxford, United Kingdom.

Emlet, R.B. 1995. Developmental mode and species geographic range in regular sea urchins (Echinodermata: Echinoidea). Evolution 49:476-89.

Excoffier, L., G. Laval \& S. Schneider. 2006. Arlequin ver. 3.0: An integrated software package for population genetics data analysis. Evol. Bioinform. 1: 47-50.

Folmer, O., M. Black, W. Hoeh, R. Lutz \& R.C. Vrijenhoek. 1994. DNA Primers for amplification of mitochondrial cytochrome c oxidase subunit I from diverse metazoan invertebrates. Mol. Mar. Biol. Biotechnol. 3: 294-299.

Fu, Y. 1997. Statistical tests of neutrality of mutations against population growth, hitchhiking and background selection. Genetics 147: 915-925.

Fu, Y. \& W. Li. 1993. Statistical tests of neutrality of mutations. Genetics 133: 693-709.

Hall, T. A. 1999. BioEdit: A user-friendly biological sequences editor and analysis program for windows 95/98 NT. Nuc. Ac. Symposium Series 41: 95-98.

Holthius, L.B. 1973. Caridean shrimps found in landlocked saltwater pools at four Indo-west Pacific localities (Sinai Peninsula, Funafuti Atoll, Maui and Hawaii Islands), with the description of one new genus and four new species. Zool. Verhandel. 128: $1-48$.

Hunter, R.L., M.S. Webb, T.M. Iliffe \& J.R. Alvarado Bremer. 2007. Phylogeny and historical biogeography of the cave-adapted shrimp genus Typhylata (Atyidae) in the Caribbean Sea and Western Atlantic. J. Biogeogr. 1: 1-11.

Iliffe, T.M. 2000. Anchialine cave ecology, p.59-76. In H. Wilkens, D.C. Culver \& W.F. Humphreys (eds.). Ecosystems of the World: Subterranean Ecosystems. Elsevier, Amsterdam, Netherlands.

Iwai, T.Y. 2005. Captive breeding of the endemic Hawaiian red shrimp, Halocaridina rubra, Part I: Reproduction, larval development, and first feeding. Division of Aquatic Resources, Hawaii Department of Land and Natural Resources, Honolulu, Hawaii, USA.

Jeffery, C.H. \& R.B. Emlet. 2003. Macroevolutionary consequences of developmental mode in temnopleurid echinoids from the tertiary of Southern Australia. Evolution 57: 1031-1048.
Kano, Y. \& T. Kase. 2004. Genetic exchange between anchialine cave populations by means of larval dispersal: the case of a new gastropod species Neritilia cavernicola. Zool. Scripta 33: 423-437.

Maciolek, J.A. 1983. Distribution and biology of IndoPacific insular hypogeal shrimps. Bull. Mar. Sci. 33: 606-618.

Mantel, N. 1967. The detection of disease clustering and a generalized regression approach. Cancer Res. 27: 209-220.

Maynard-Smith, J. \& J. Haigh. 1974. The hitchhiking effect of a favorable gene. Gen. Res. 23: 23-35.

Miller, J.M. \& D.J. Ayre. 2008. Population structure is not a simple function of reproductive mode and larval type: insights from tropical corals. J. Anim. Ecol. 77: 713-724.

Miller, M.P. 2005. ALLELES IN SPACE (AIS): computer software for the joint analysis of interindividual spatial and genetic information. J. Hered. 96: 722-724.

Nielsen R. \& M. Slatkin. 2000. Likelihood analysis of ongoing gene flow and historical association. Evolution 54: 44-50.

Nielsen, R. \& J. Wakeley 2001. Distinguishing migration from isolation: A Markov Chain Monte Carlo approach. Genetics 158: 885-896.

Page, T.J., W.F. Humphreys \& J.M. Hughes. 2008. Shrimps down under: evolutionary relationships of subterranean crustaceans from Western Australia (Decapoda: Atyidae: Stygocaris). PLoS ONE 3: 1-12.

Palumbi, S.R. 1994. Genetic divergence, reproductive isolation, and marine speciation. Ann. Rev. Ecol. Syst. 25: 547-572.

Palumbi, S.R. 1995. Using genetics as an indirect estimator of larval dispersal. In McEdward, L. (ed.). Ecology of Marine Invertebrate Larvae. CRC, Florida, USA.

Palumbi, S.R. 2003. Population genetics, demographic connectivity, and the design of marine reserves. Ecol. Appl. 13: 146-158

Posada, D., K.A. Crandall \& A.R. Templeton. 2000. GeoDis: A program for cladistic nested analysis of the geographical distribution of genetic haplotypes. Mol. Ecol. 9: 487-488.

Posada, D., K.A. Crandall \& A.R. Templeton. 2006. Nested clade analysis statistics. Mol. Ecol. Notes 6: 590-593. 
Rivera, M.A.J., C.D. Kelley \& G.K. Roderick. 2003. Subtle population genetic structure in the Hawaiian grouper, Epinephelus quernus (Serranidae) as revealed by mitochondrial DNA analyses. Biol. J. Linnean Soc. 81: 449-468.

Rousset, F. 1997. Genetic differentiation and estimation of gene flow from F-statistics under isolation by distance. Genetics 145: 1219-1228.

Rozas, J., J.C. Sanchez-DelBarrio, X. Messeguer \& R. Rozas. 2003. DNASP, DNA polymorphism analyses by the coalescent and other methods. Bioinformatics 19: 2496-2497.

Santos, S.R. 2006. Patterns of genetic connectivity among anchialine habitats: a case study of the endemic shrimp Halocaridina rubra on the island of Hawaii. Mol. Ecol. 15: 2699-2718.

Sket, B. 1996. The ecology of anchialine caves. Trends Ecol. Evol. 11: 221-225.

Slatkin, M. 1991. Inbreeding coefficients and coalescence times. Genet. Res. 58: 167-175.

Strathmann, R.R. 1985. Feeding and nonfeeding larval development and life history evolution in marine invertebrates. Annu. Rev. Ecol. Syst. 16: 339-361.
Tamura, K. \& M. Nei. 1993. Estimation of the number of nucleotide substitutions in the control region of mitochondrial DNA in humans and chimpanzees. Mol. Biol. Evol. 10: 512-526.

Tajima, F. 1989. Statistical method for testing the neutral mutation hypothesis by DNA polymorphism. Genetics 123: 597-601.

Templeton, A.R., E. Routman \& C.A. Phillips. 1995. Separating population structure from population history: a cladistic analysis of the geographical distribution of mtDNA haplotypes in the tiger salamander, Ambystoma tigrinum. Genetics 140: 767-782.

Templeton, A.R. 1998. Nested clade analyses of phylogeographic data: testing hypotheses about gene flow and population history. Mol. Ecol. 7: 381-397.

Waples, R.S. 1998. Separating the wheat from the chaff: patterns of genetic differentiation in high gene flow species. J. Hered. 89: 438-450.

Wright, S. 1943. Isolation by distance. Genetics 28:114-138.

Wright, S. 1978. Evolution and the genetics of populations. Vol. 4. Variability within and among natural populations. Chicago University, Chicago, USA. 